\title{
Prevalence of musculoskeletal disorders among staffs in specialized healthcare centre
}

\author{
Nurul Ikhmar Ibrahim* and Devinthiran Mohanadas \\ School of Manufacturing Engineering, University of Malaysia Perlis (UniMAP), Perlis, Malaysia
}

\begin{abstract}
This study was conducted to investigate pervasiveness of the musculoskeletal disorder (MSD) among staffs in a specialized healthcare centre. Sixty-eight staffs from three departments namely Cardiovascular Lab (CVL), Nuclear Radiology, and General Radiography were recruited in this study. A modified Nordic Musculoskeletal Questionnaire (NMQ) was distributed among study population. The result shows that the prevalence of MSD was highest in lower back (88.2\%), neck (76.5\%) and shoulder (60.3\%) for the past 12 months followed by lower back and elbow (44.1\%), and wrist (39.1\%) correspondingly, for the past 7 days. Present results suggest that healthcare professionals - radiographers, patient assistants and nurses incurs MSD risks through work tasks as well as psychosocial factors. These include awkward posture during patient handling, workload, work stress and time pressure. Therefore, an ergonomics improvement on the job design and workspace are needed in order to reduce the MSD risks.
\end{abstract}

Keywords: prevalence, MSD, healthcare professionals, psychosocial

\section{Introduction}

Musculoskeletal disorder (MSD) is an umbrella term to describe health problems that commonly affect the musculoskeletal system of the body. The significant effects of MSD includes difficulty in performing manual tasks, difficulty in exerting forces and restrictions of movement due to pain, or loss of function. Many workers from a wide variety of occupations had been affected and had caused a major impact to several organizations. World Health Organization, WHO (2011) classify MSD as a major cause of absence from work and, lead therefore, to considerable cost for the public health system [15].

In general, MSD is most prevalent occupational problem in manufacturing and heavy labour industries. Apparently, few epidemiological studies have investigated MSD risk factors among healthcare professionals. This include studies reported in Asian region that focuses on same area of interest; the MSD among nurses in healthcare environment [11-12]. However, there were no significant studies reported on other healthcare professionals particularly radiog- raphers, patient assistants and nurses in a specialized healthcare centre. Hence, this study intends to evaluate the pervasiveness of the MSD among staffs in a specialized healthcare centre in an ASEAN country. The primary objective is to investigate the prevalence of musculoskeletal problems due to manual handling tasks.

\section{Methods}

\subsection{Study population}

This study was conducted at a specialised healthcare centre in Singapore. A total of 68 staffs from three departments namely Cardiovascular Lab (CVL), Nuclear Radiology, and General Radiography were involved in this study. Participants were selected based on working experience of more than one year, free from physical illness or disorder and involved in manual handling activities.

\footnotetext{
${ }^{*}$ Corresponding author. Nurul Ikhmar Ibrahim, School of Manufacturing Engineering, Main Campus Pauh Putra, University of Malaysia Perlis (UniMAP), 02600 Arau, Perlis, Malaysia. E-mail: ikhmar@unimap.edu.my, Tel. no. +6049885086, Fax no. +6049885034
} 


\subsection{Questionnaires}

A modified Nordic Musculoskeletal Questionnaire (NMQ) was distributed among study population in two means; firstly, it was delivered through e-mail and secondly it was handed manually during staff's recess period and was collected thereafter. The questionnaire was divided into three sections - background information, nature and demand of job, and body part discomfort survey.

\section{Results}

\subsection{Demographic characteristics}

The result of demographic characteristics of all workers in all three departments is shown in Table 1. From all valid respondents, it shows that the majority of staffs were female $(n=52)$ which accounts about $76.5 \%$ of total staffs in all three departments. The mean age for females staffs were 33.1 years old while the male staffs was 36.7 years old. Most of the females staffs had mean height of $1.61 \mathrm{~cm}$ while the males accounted $1.77 \mathrm{~cm}$ in height. The mean employment record for female was 3.1 years compared to males with 3.56 years employment record. Majority of the staffs had educational level of bachelor's degree $(n=36)$ followed by diploma $(n=23)$ and Master/PHD $(n=9)$.

\subsection{MSD prevalence}

Based on Table 2, the highest prevalence of MSD during the last 12 months were found in Nuclear Radiology department (77.2\%), followed by CVL department $(72.2 \%)$ and General Radiography department $(50 \%)$. The highest prevalence of MSD in the last 7 days were found in CVL department (47.2\%) followed by Nuclear Radiology department (36.4\%) and General Radiography department (20\%).

Overall, there is a high percentage of prevalence of MSD in all three departments with $70.6 \%$ during the last 12 months and $39.7 \%$ during the last 7 days.

Next, the prevalence of musculoskeletal disorders in 9 body parts during the last 12 months and last 7 days are shown in Table 3 and Table 4 respectively. Feedback from Nuclear Radiology department shows that staffs had highest reported of MSD on hip and lower back which accounted at $81.1 \%$ and $77.2 \%$ respectively.
In CVL department, most complaints were reported for MSD on lower back and neck, each accounted $94.4 \%$ respectively. The highest prevalence of MSD in General Radiography department was on lower back $(90 \%)$ followed by shoulder $(50 \%)$. In

\section{Table 1}

Demographic characteristics

\begin{tabular}{lll}
\hline Demographics & Female & Male \\
\hline $\begin{array}{l}\text { Number of respondent } \\
\text { (n) }\end{array}$ & 52 & 16 \\
Age (years) & & \\
Mean & 33.1 & 36.7 \\
SD & 7.16 & 5.62 \\
Weight (kg) & & \\
Mean & 67.21 & 67.03 \\
SD & 6.37 & 9.21 \\
Height (cm) & 1.61 & 1.77 \\
Mean & 0.04 & 0.15 \\
SD & & \\
Duration of \\
employment
\end{tabular}


Table 2

Prevalence of MSD during the last 12 months and 7 days by each department

\begin{tabular}{|c|c|c|c|c|}
\hline Department & $\begin{array}{l}\text { Valid } \\
\text { responded (n) }\end{array}$ & Gender & $\begin{array}{l}\text { Last } 12 \text { months } \\
\text { n (\%) }\end{array}$ & $\begin{array}{l}\text { Last } 7 \text { days } \\
\text { n (\%) }\end{array}$ \\
\hline Nuclear Radiology & 22 & $\begin{array}{l}\text { Female }(n=14) \\
\text { Male }(n=8) \\
\text { Total }(n=22)\end{array}$ & $\begin{array}{l}12(54.5) \\
5(62.5) \\
17(77.2)\end{array}$ & $\begin{array}{l}6(42.8) \\
2(25) \\
8(36.4)\end{array}$ \\
\hline CVL & 36 & $\begin{array}{l}\text { Female }(n=31) \\
\text { Male }(n=5) \\
\text { Total }(n=36)\end{array}$ & $\begin{array}{l}24(80) \\
2(33.3) \\
26(72.2)\end{array}$ & $\begin{array}{l}16(53.3) \\
1(16.6) \\
17(47.2)\end{array}$ \\
\hline General Radiology & 10 & $\begin{array}{l}\text { Female }(n=7) \\
\text { Male }(n=3) \\
\text { Total }(n=10)\end{array}$ & $\begin{array}{l}4(57.1) \\
1(33.3) \\
5(50)\end{array}$ & $\begin{array}{l}2(28.6) \\
0(0) \\
2(20)\end{array}$ \\
\hline Total & 68 & $\begin{array}{l}\text { Female }(n=52) \\
\text { Male }(n=16) \\
\text { Total }(n=68)\end{array}$ & $\begin{array}{l}40(78.4) \\
8(47) \\
48(70.6)\end{array}$ & $\begin{array}{l}24(47) \\
3(17.6) \\
27(39.7)\end{array}$ \\
\hline
\end{tabular}

Table 3

Prevalence of MSD in 9 body parts for the last 12 months

\begin{tabular}{|c|c|c|c|c|}
\hline & \multicolumn{4}{|c|}{ Department } \\
\hline & $\begin{array}{l}\text { All } \\
\mathrm{n}(\%)\end{array}$ & $\begin{array}{l}\text { Nuclear } \\
\text { Radiology } \\
\mathrm{n}(\%)\end{array}$ & $\begin{array}{l}\text { CVL } \\
\text { n (\%) }\end{array}$ & $\begin{array}{l}\text { General } \\
\text { Radiography } \\
\mathrm{n}(\%)\end{array}$ \\
\hline Neck & $52(76.5)$ & $14(63.6)$ & $34(94.4)$ & $4(40.0)$ \\
\hline Shoulder & $41(60.3)$ & $7(31.8)$ & $29(80.5)$ & $5(50.0)$ \\
\hline Elbow & $30(44.1)$ & $0(0.0)$ & $27(75.0)$ & $3(30.0)$ \\
\hline Wrist & $36(52.9)$ & $9(40.9)$ & $23(63.8)$ & $4(40.0)$ \\
\hline Upper back & $27(39.7)$ & $13(59.0)$ & $12(33.3)$ & $2(20.0)$ \\
\hline Lower back & $60(88.2)$ & $17(77.2)$ & $34(94.4)$ & $9(90.0)$ \\
\hline Hip & $20(29.4)$ & $4(81.1)$ & $13(36.1)$ & $3(30.0)$ \\
\hline Knee & $11(16.2)$ & $0(0.0)$ & $9(25.0)$ & $2(20.0)$ \\
\hline Ankle & $29(42.6)$ & $0(0.0)$ & $28(77.0)$ & $1(10.0)$ \\
\hline
\end{tabular}


Table 4

Prevalence of MSD in 9 body parts for the last 7 days

\begin{tabular}{lllll}
\hline & Department & & \\
\cline { 2 - 5 } & All & $\begin{array}{l}\text { Nuclear } \\
\text { Radiology } \\
\mathrm{n}(\%)\end{array}$ & $\mathrm{CVL}$ & $\begin{array}{l}\text { General } \\
\text { Radiography } \\
\mathrm{n}(\%)\end{array}$ \\
\hline Neck & $19(27.9)$ & $2(9.0)$ & $13(36.1)$ & $4(40.0)$ \\
Shoulder & $26(38.2)$ & $0(0.0)$ & $25(69.4)$ & $1(10.0)$ \\
Elbow & $30(44.1)$ & $0(0.0)$ & $27(75.0)$ & $3(30.0)$ \\
Wrist & $27(39.7)$ & $0(0.0)$ & $23(63.8)$ & $4(40.0)$ \\
Upper back & $20(29.4)$ & $7(31.8)$ & $12(33.3)$ & $1(10.0)$ \\
Lower back & $30(44.1)$ & $9(40.9)$ & $15(41.6)$ & $6(60.0)$ \\
Hip & $3(4.4)$ & $0(0.0)$ & $3(8.3)$ & $0(0.0)$ \\
Knee & $9(13.2)$ & $0(0.0)$ & $8(22.0)$ & $1(10.0)$ \\
Ankle & $6(8.8)$ & $0(0.0)$ & $1(3.0)$ & $5(50.0)$ \\
\hline
\end{tabular}

conclusion, MSD on lower back was reported as the highest prevalence of MSDs among staffs in all three departments for the past 12 months.

In contrast, the overall 7 days period in prevalence of any MSD at any body part was ranged between $9 \%$ in Nuclear Radiology to $60 \%$ in the General Radiography department. By individual body part, the most commonly reported category was the lower back, with $40.9 \%$ at Nuclear Radiology department and $60 \%$ at General Radiography department. For CVL department, the highest reported MSD was on elbow with $75 \%$. Second highest MSD was the upper back (Nuclear Radiology), shoulder (CVL) and ankle (General Radiography) with a percentage of $31.8 \%, 69.4 \%$ and $50 \%$ respectively. Moreover, the wrist was identified as one of the highest complaint for MSD particularly for CVL $(63.8 \%)$ and General Radiography (40\%) departments, while there were no complaints at Nuclear Radiology department. This is followed by MSD on the neck with prevalence varied from 9\% (Nuclear Radiology) to 40\% (General Radiography).

In general, MSD on the hip and the ankle were the least with no reported case in both Nuclear Radiology and General Radiography with few staffs from CVL department reported of MSD on hip and ankle. In comparison of the least or no reported cases of particular body part, Nuclear Radiology department had only MSD complaints on upper back, lower back and neck whereas the rest had no reported symptoms on MSD. The other two departments had reported cases on all body parts with minimum occurrence of at least 1 case on each body part. However, there no reported cases of MSD on hip in General Radiography department.

Overall, the pain location at lower back and elbow were the commonly reported affected area with each presented $44.1 \%$. This is followed by pain at the wrist $(39.7 \%)$ and shoulder (38.2\%).

\subsection{Work factors association with MSD}

Frequency of pain on 9 body parts was compared between work factors to identify its association with MSD. Table 5 presents this relationship where the work factors are divided into posture, workload (time) and duration of employment. 


\subsubsection{Posture}

Based on Table 5, strenuous tasks involving lifting, pushing and pulling had reported the highest occurrence of MSD on lower back with $96 \%$. For the same tasks, the second highest was the neck which marked $84 \%$ followed by ankle (76\%), shoulder $(72 \%)$ and upper back $(68 \%)$. For tasks that require sitting, the frequency of pain was highest at shoulder with $76 \%(\mathrm{n}=19)$ and lower back with $68 \%(n=17)$. Generally, for all postures, those who had reported of the lower back pain had also indicated that they suffered MSD at shoulders and neck.

The result indicates that sitting and awkward posture involving lifting, pushing and pulling tasks put greater demands on body parts and consequently contributes to MSD.

\subsubsection{Workload (time)}

The MSD association with workload (time) are generally ascertained based on the duration of work load which are classified into 4 groups.

Lower back was the highest reported MSD by staffs with more than 1 hour of working time. This was obvious for staffs that performed work of more than 4 hours with prevalence of $50 \%$. Similarly, workload of between 2 to 3 hours had resulted in $100 \%$ occurrence. Besides that, shoulder MSD was found to be the second highest for workload of more than 2 hours

Next, for workload of less than 2 hours, other than lower back MSD also was reported on knee $(45.5 \%)$, neck $(27.3 \%)$ and wrist $(30 \%)$. Then, for those performed on workload of less than 1 hour there were only few reported cases of related pain on body parts.

In conclusion, lower back and shoulder were the most common problem for working hours of more than 2 hours.

\subsubsection{Duration of employment}

Findings from this study showed that staffs with more than 5 years employment had very low incidence of MSD related pain on their body parts compared to that staffs in employment records of less than 5 years. The reason might be due to the job position and staff's level of knowledge on workplace safety.
The result did not have such an impact despite in some context it may have regarded to happen proportionally to number of years the staffs have tenured in the particular department.

\subsection{Association between MSD and job demand/psychosocial}

\subsubsection{Gender}

From tabulated data of gender ratio of male to female, it was obvious that greater part of the population was predominantly female staffs in all departments. Relevant study of relationship between the gender factors associated with MSD had pointed that female staffs showed higher risk of having MSD. In the survey, $98 \%$ of female staffs had reported of low back pain compared to male staffs which only accounted $8 \%$ of the their counterpart.

Other than lower back female staffs complaint of having pain on shoulder $(86.5 \%)$ and knee $(40,4 \%)$. On contrary, male staffs had pain on ankle $(68.8 \%)$ and neck $(62.5 \%)$.

On the whole, apparently male staffs had much lower case of MSD symptom on their body parts compared to female staffs.

\subsubsection{Work stress}

Although there are only few epidemiological studies regarding MSD prevalence associated with work stress, the fact if a person have mentally demanded for high stressful task, illness may occur due to lack of rest and repetitive job. The survey on this particular section had implied relevance in MSD prevalence. Unpredictably, $75 \%$ of the staffs in all departments had agreed that they had work stress in which they had also indicated that they have had experienced MSD on their body parts. The highest reported was on lower back $(98 \%)$ followed by knee $(88.2 \%)$, and shoulder and ankle $(62.7 \%)$.

\subsubsection{Time pressure}

The survey among the staffs had similar response to work stress factor with $75 \%$ agreed on time pressure had an effect to their body pain. The result was similar to work stress with that lower back, knee, 
shoulder and ankle were the highest frequency of reported pain. While, wrist MSD was the least with only $3.9 \%$.

\subsubsection{Physical demand}

Staffs were also asked on the physical demand or the difficulty of the task in their daily job. It was found that $87.7 \%$ of the staffs in all departments admit that they involved in task that demands physical strength. Staffs had complained of MSD on lower back, shoulder, and wrist and neck that account $98.4 \%, 93.4 \%, 77 \%$, and $72.1 \%$ respectively.

\section{Discussion}

Results demonstrate that prevalence of MSD is most common at lower back. Other body regions include neck, shoulder and upper back. This study is similar to other studies made by other researchers which show the low back pain as the highest reported cases for healthcare professionals $[11-13,16]$. 


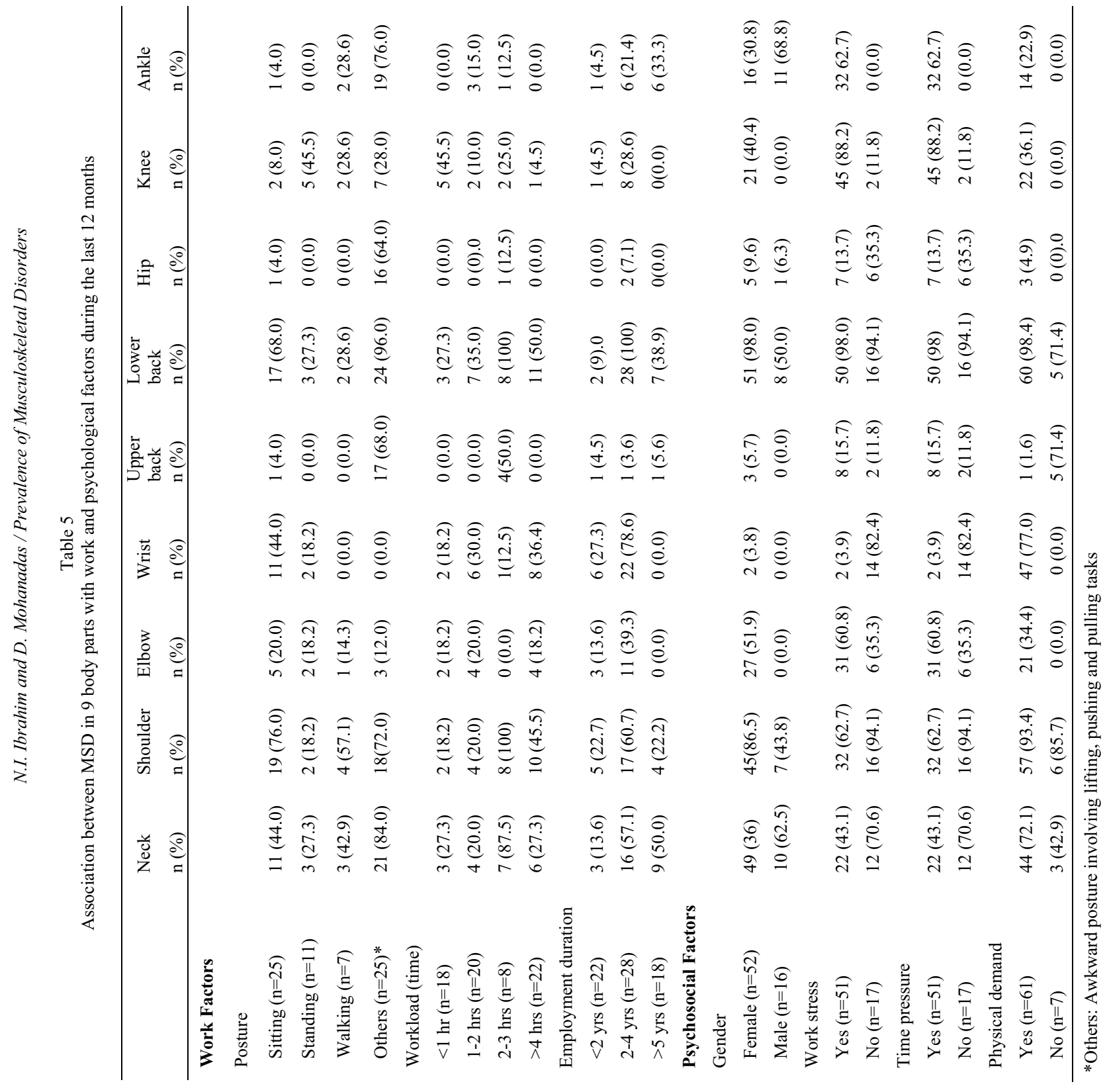


Pain at shoulder and neck were also common musculoskeletal problems among the staffs. From the survey, prevalence of MSD at neck and shoulder associated with work factor for the past 12 months showed high rate of reported case when compared to lower back. Existing studies showed that the three highest prevalence rates of MSD for nurses were found for the neck, shoulders and back, followed by the upper back, hands/wrist and knee/lower legs [5].

\subsection{Factors associated with MSD}

Work task and psychosocial factors were found to increase the prevalence of MSD among the staffs. Characteristics of work task of all departments typically involves transferring of patients from gurney, repositioned patient in bed side to side, manoeuvring the X-ray tube, pushing/pulling of overhead vertical $\mathrm{X}$-ray machine, as well as working at computer workstation that requires prolonged seated position results in high prevalence of lower back and upper extremity disorders. Previous researches had found relationship of work posture to MSD. For example, prolonged sitting position was related to musculoskeletal symptoms of neck, shoulder and lower back $[1,9]$. This might be that workers have prolonged static posture to perform manual task with arms elevated and involving excessive hand equipment [3].

An explanation for this occurrence is that being in static posture for long time, the veins and capillaries inside the muscles are compressed resulting in lack of oxygen and nutrition in the tissues causing micro trauma of those muscles. Micro trauma can cause imbalance, fatigue, discomfort and pain of the tissues [10].

Furthermore, working postures with sustained or constrained posture, such as task requires movement of upper extremity that eventually force neck and shoulders aligned awkwardly can contribute to development of musculoskeletal disorders of neck and shoulder $[2,8,10]$. In all three departments, it is common to see staffs performing tasks that require reaching above shoulder level, reaching in front of the body, or twisting of arms. Example is the radiographers that handle the overhead X-ray machine. It was further proven by Kumar, Moro and Narayan (2004) where X-ray technologists had significant low back and upper extremity problems due to the forceful movement of the shoulder and wrist/hand [6].

MSD had been associated with psychosocial work factors such as gender, mood, work stress, pre- menstrual tension, high mental pressure and job dissatisfaction $[13,16,17]$.

In this study, duration of employment was found to have little influence to the prevalence of MSD. This is consistent with previous study conducted among Japanese rural nurses where it had shown that duration of work is not significantly associated with MSD prevalence [12]. However, another research done by Yip (2001) had pointed out that current job position, educational level and experience within employment years had incidence rate of low back pain among nurses [17].

High workload was found to be significant to prevalence of MSD with working time of more than 2 hours. This high workload can be related to the work stress and time pressure experienced by $75 \%$ of 68 respondents that participated in this study. Study done by Lim and Pinto (2009) on radiologist workload had identified important factors that increase stress, which include high overall volume of work, increase pressure to meet deadlines and disruption of home life due to long hours at work [7].

As for gender, most female staffs working in all three departments were found to have higher case of MSD symptom compared to male staffs. It may due to high demands of physical strength cause by manual handling tasks.

\section{Conclusion}

Present results indicate that healthcare professionals - radiographers, patient assistants and nurses are exposed to MSD risks particularly on the lower back, shoulder, neck and wrist/hand. The work task and psychosocial factors were identified as the main cause of MSD among the staffs. Therefore, an ergonomics improvement on the job design and workspace are needed in order to reduce the MSD risks.

\section{References}

[1] Canadian Centre for occupational Health and Safety (2005). Work-related musculoskeletal disorders (WMSDs). Retrieved from http://www.ccohs.ca/oshanswers/diseases/rmirsi.html.

[2] Centers for Disease and Control Prevention (2011). Ergonomics and Musculoskeletal disorders. Retrieved from http://www.cdc.gov/niosh/topics/ergonomics .

[3] Herberts, P., Kadefors, R., Hogfors, C. \& Sigholm, G. (1984). Shoulder pain and heavy manual labour. Clinical Orthopaedic \& Related Research,191,166-78.

[4] Hignett, S. (1996). Postural analysis of nursing work. Applied Ergonomics, 27, 171-176. 
[5] Daraiseh, N., Genaidy, A.M., Karwowski, W., Davis, L.S., Stambough, J. \& Huston, R.L. (2003). Musculoskeletal outcomes in multiple body regions and work effects among nurses: the effects of stressful and stimulating working conditions, Ergonomics, 46 (12), 1178-1199.

[6] Kumar, S., Lil Moro \& Narayan, Y. (2004). Perceived physical stress at work and musculoskeletal discomfort in X-ray technologists. Ergonomics, 47 (2), $189-201$.

[7] Lim, R.H.C. \& Pinto, C. (2009). Work stress, satisfaction and burnout in New Zealand radiologists: Comparison of public hospital and private practice in New Zealand. Journal of Medical Imaging and Radiation Oncology, 53, 194199.

[8] National Institute for Occupational Safety and Health, Rosenstock, L. (1997). Occupational musculoskeletal disorders: The subcommittee on workforce protection.

[9] Pope, M.H., Goh, K.L. \& Magnusson, M.L. (2002). Spine ergonomics. Annual Review of Biomedical Engineering, 4,49-68.

[10] Rubenowitz, S. (1997) Survey and intervention of ergonomic problems at the workplace. International Journal of Industrial Ergonomics, 19, 271-275.

[11] Smith, D.R., Choi, Jae-wook, Myung Ki, Kim, Jae-young, \& Yamagata, Z. (2003a) Musculoskeletal disorders among staff in South Korea's largest nursing home. Environmental Health and Preventive Medicine, 8 (1), 23-28.
[12] Smith, D.R., Kondo, N., Tanaka, E., Hirasawa, K. \& Yamagata, Z. (2003b). Musculoskeletal disorders among hospital nurses in rural Japan. Rural and Remote Health, 3, 241.

[13] Smith, D.R., Mihashi, M., Adachi, Y., Koga, H. \& Ishitake, T. (2006). A detailed analysis of musculoskeletal disorder risk factors among Japanese nurses. Journal of Safety Research, 37, $195-200$.

[14] Stubbs, B. (2009). The manual handling of the aggressive patient: a review of the risk of injury to nurses. Journal of Psychiatric and Mental Health Nursing, 16, 395-400.

[15] World Health Organization (WHO) (2011). Occupational Health Publication: Musculoskeletal disorders. Retrieved from

http://www.who.int/occupational_health/publications/oehms d3.pdf

[16] Yeung, S.S., Genaidy, A. \& Levin, L. (2004). Prevalence of musculoskeletal symptoms among Hong Kong nurses. Occupational Ergonomics, 4, 199-208.

[17] Yip, Y.B. (2001). A study of work stress, patient handling activities and the risk of low back pain among nurses in Hong Kong. Journal of Advanced Nursing, 36 (6), 794-804. 